\title{
Perilaku Konsumtif Nelayan Anak di Pasir Kandang Kelurahan Pasie Nan Tigo Kecamatan Koto Tangah Padang
}

\author{
Nandini Afistan, Alia Azmi \\ Prodi Pendidikan Pancasila dan Kewarganegaraan \\ FIS Universitas Negeri Padang \\ E-mail: nandiniafistan@gmail.com
}

\section{ABSTRAK}

Artikel ini bertujuan untuk mengetahui kegiatan nelayan anak di Pasir Kandang Kelurahan Pasie Nan Tigo Kecamatan Koto Tangah Padang, perilaku nelayan anak dalam menggunaka uangnya, dan dampak negatif nelayan anak di Pasir Kandang. Jenis penelitian adalah penelitian deskriptif dengan pendekatan kualitatif. Informan penelitian yaitu nelayan anak, orang tua, masyarakat Pasir Kandang. Teknik pengumpulan data yang digunakan dalam penelitian ini yaitu observasi, wawancara, dan dokumentasi. Teknik analisis data dalam penelitian ini yaitu pengumpulan data, reduksi data, penyajian data, penarikan kesimpulan, dan verifikasi. Hasil penelitian ini menunjukan nelayan anak memilih bekerja menjadi seorang nelayan di banding bersekolah di usia sekolah, karena sudah mampu menghasilkan uang sendiri dan memiliki pola hidup yang konsumtif, dengan membeli barang-barang mahal, kendaraan pribadi dan mencari hiburan malam.Hal ini diharapkan agar nelayan anak di Pasir Kandang Kelurahan Pasie Nan Tigo Kecamatan Koto Tangah Padang, sebaiknya lebih mementingkan sekolah agar memiliki taraf hidup yang lebih baik, semakin tinggi pendidikan kita semakin mudah kita mendapatkan pekerjaan dan kehidupan yang terjamin.

Kata Kunci: nelayan anak, sekolah, perilaku konsumtif

\section{ABSTRACT}

This article aims to find out the activities of child fishermen in Pasir Kandang Kelurahan Pasie Nan Tigo Koto Tangah Padang Sub-District, to know the behavior of child fishermen in using the money, and the negative impact of child fishermen in Pasir Kandang. This type of research is descriptive research with a qualitative approach. Research informants are child fishermen, parents, pasir kandang community. The data collection techniques used in this study are observation, interview, and documentation. The data analysis techniques in this study are data collection, data reduction, data presentation, conclusion drawing, and verification. The results of this study show that children choose to work as fishermen in school age, because they are able to make their own money and have a consumptive lifestyle, by buying expensive goods, private vehicles and looking for nightlife. It is expected that children fishermen in Pasir Kandang Kelurahan Pasie Nan Tigo Koto Tangah Padang sub-district, 
should be more concerned with schools to have a better standard of living, the higher our education the easier we get a job and a guaranteed life.

Keywords: child fisherman, school, consumptive behavior

(c) (i) (?) This work is licensed under the Creative Commons Attribution-ShareAlike 4.0 International License. EY SA 02020 by author. 


\section{PENDAHULUAN}

Nelayan anak di Pasir Kandang Kelurahan Pasie Nan Tigo Kec. Koto Tangah Padang lebih memilih bekerja sebagai nelayan di bandingkan bersekolah di usia sekolah, karena sekolah dapat mengekang dan mengatur hidup nelayan anak. Padahal pendidikan merupakan hal terpenting dalam kehidupan.

Dalam Undang-Undang Nomor 20 Tahun 2003 tentang sistem pendidikan Nasional disebutkan bahwa "Pendidikan adalah usaha sadar dan terencana untuk mewujudkan suasana belajar dan proses pembelajaran agar peserta didik secara aktif mengembangkan potensi dirinya agar memiliki kekuatan keagamaan, pengendalian diri, kepribadian, kecerdasan, akhlak mulia, serta keterampilan diperlukan dirinya, masyarakat, bangsa dan negara". Pendidikan itu wajib namun anak-anak di Pasir Kandang lebih memilih putus sekolah dan memilih bekerja di pantai daripada bersekolah.

Di daerah Pasir Kandang masih banyak anak yang putus sekolah karena kurangnya kesadaran akan pentingnya pendidikan. Sebagaimana diketahui di Pasir Kandang Kelurahan Pasir Nan Tigo Kecamatan Koto Tangah Padang anak usia sekolah lebih memilih bekerja dari pada bersekolah. Sebab perekonomian di daerah tersebut tergolong rendah sehingga anak memilih bekerja di pantai. Berdasarkan pengamatan perilaku anak-anak nelayan di Pasir Kandang, mereka melaut dengan waktu 3-7 hari untuk mencari ikan tangkapan, dan baru kembali kedaratan karena kejenuhan melaut. Mereka mencari hiburan dengan pilihan hiburan malam. Selain hiburan malam mereka juga membeli kendaraan pribadi seperti sepeda motor dan mobil, membeli pakaian dengan merek mahal, serta berteman dengan orang-orang yang memiliki materi lebih untuk mencari pergaulannya dan menjadikan itu sebagai hobi. Setelah mewawancarai anak-anak nelayan di Pasir Kandang, mereka tidak berminat untuk bersekolah karena tujuan akhir sekolah untuk mencari pekerjaan dan menghasilkan uang. Sedangkan kenyataan yang terjadi pada mereka sekarang tanpa bersekolahpun, dengan cara melaut mereka dapat menghasilkan uang dan bisa membeli apa saja dengan uang yang di hasilkannya. Hal ini mengarahkan mereka pada perilaku yang mengutamakan keuntungan untuk dirinya.

Penelitian yang relevan dengan penelitian ini adalah penelitian yang dilakukan oleh 
Prayitno (2017) tentang Fenomena Anak Putus Sekolah di Kelurahan Pasie Nan Tigo Pasie Jambak. Penelitian ini dilatar belakangi oleh rendahnya ekonomi keluarga yang menemukan masih banyak anak putus sekolah di tahun 2015 terdapat 30 orang anak putus sekolah di sekolah dasar, 17 orang SMP, 4 orang SMA. Faktor penyebab anak putus sekolah pada umumnya disebabkan oleh faktor ekonomi dan upaya pemerintah, masyarakat, dan orangtua belum maksimal.

Kemudian penelitian oleh (Hengki Tarman: 2013) tentang faktor-faktor Penyebab Anak Putus Sekolah (Studi kasus di Kelurahan Banuaran di Kecamatan Lubuk Begalung Padang). Hasil penelitian ini menunjukan bahwa faktor penyebab anak putus sekolah di Kelurahan Banuaran ada tiga yaitu: Pertama faktor keluarga, kurangnya perhatian dari orangtua terhadap pendidikan anak. Kedua faktor lingkungan, terpengaruhnya anak oleh pengaruh lingkungan yang tidak baik, dan faktor ekonomi yakni ketidaksanggupan dalam membiayai pendidikan anak.

Adapun perbedaan penelitian ini dengan penelitian terdahulu yaitu memfokuskan kepada nelayan anak yang putus sekolah dengan gaya hidup yang konsumtif. Penyebabnya karena faktor lingkungan, faktor ekonomi orangtua yang rendah, kurangnya perhatian orang tua dan rasa sudah puas dengan bisa memiliki penghasilan sendiri, serta mencari hiburan malam untuk kesenangan pribadi, membeli barang-barang mahal, hingga hamil di luar nikah. Kelebihan solusi yang di tawarkan dalam artikel ini adalah peneliti menemukan anak memilih putus sekolah bukan semata-mata karena rendahnya ekonomi keluarga namun karena ia merasa sudah mampu menghasilkan uang sendiri sendiri serta membeli barangbarang mahal, kendaraan pribadi, mencari hiburan malam, dengan pola hidup yang konsumtif.

\section{METODE PENELITIAN}

Penelitian ini menggunakan metode penelitian kualitatif deskriptif. Lokasi penelitian di Pasir Kandang Kelurahan Pasie Nan Tigo Kecamatan Koto Tangah Padang. Informan penelitian menggunakan teknik purposive sampling dimana informan dipilih berdasarkan pada orang-orang yang benar-benar memahami permasalahan yang peneliti teliti. Informan dalam penelitian ini adalah nelayan anak di Pasir Kandang, orang tua, serta masyarakat Pasir Kandang. Teknik pengumpulan data dilakukan melalui observasi, wawancara, studi dokumentasi. Uji keabsahan 
data penulis menggunakan teknik triangulasi sumber dan data yang di peroleh akan di analisis melalui tahap reduksi data, penyajian data dan penarikan kesimpulan lalu di verifikasi.

\section{HASIL DAN PEMBAHASAN}

Dari hasil penelitian diatas telah diperoleh gambaran tentang profil nelayan anak di Pasir Kandang Kelurahan Pasie Nan Tigo Kec. Koto Tangah Padang. Peneliti menemukan 30 orang nelayan anak memilih untuk bekerja sebagai nelayan di banding bersekolah, 17 orang di antaranya pada usia sekolah, 13 orang dalam usia tidak sekolah.

Dari hasil observasi dan wawancara peneliti menemukan kegiatan yang dilakukan nelayan anak di Pasir Kandang lakukan setiap harinya bekerja sebagai nelayan lalu bermain dengan dengan teman, mencari hiburan malam, duduk-duduk di beton hingga larut malam, minumminuman keras dan meresahkan warga. Dari 30 nelayan anak yang saya wawancara tidak ada satu orang pun dari nelayan anak yang masih bersekolah namun merasa puas dengan penghasilan sendiri.

Banyak dari nelayan anak yang membuat kekacauan dilingkungan Pasir Kandang, seperti berkelahi dengan anak Pasir Jambak, berjudi, minum-minuman keras, memakai pisau atau bendabenda tajam lainnya untuk berkelahi dan tindakan kriminalitas yang tidak wajar di lakukan seumurnya.

Hal ini disampaikan oleh Sugeng Arianto (2001) yang menyatakan dampak negatif dari anak putus sekolah, yaitu: kenakalan remaja, seperti pacaran, pencurian dan perkelahian, pesta miras, menonton pornografi dan mengganggu teman (Musfiqon, 2007:24).

Berdasarkan temuan peneliti di lapangan, dari 30 orang yang di wawancarai atas perilaku nelayan anak menggunakan uangnya, 25 orang diantaranya menggunakan uang untuk memenuhi rasa kepuasan tersendiri.

Dalam kehidupan seharihari nelayan anak memiliki perilaku yang tidak wajar, perilaku yang dimiliki nelayan anak ini banyak memberikan efek negatif saja. Penghasilan mereka hanya digunakan untuk memenuhi keinginan yang bukan kebutuhan, apalagi membantu orang tua. Disebabkan oleh penghasilan yang besar, dimana penghasilan serendahnya 50 ribu rupiah hingga 2 juta rupiah, nelayan anak di Pasir Kandang menggunakan uangnya untuk membeli pakaian mahal, jam tangan, ponsel, hingga kendaraan pribadi, seperti sepeda motor dan 
mobil. Hal yang lebih miris nelayan anak menggunakan uang untuk kesenangan di malam hari, mencari hiburan malam, duduk di tongkrongan kafe kopi, menggunakan uang untuk berpacaran, hingga hiburan ke diskotik, minum-minuman keras dan menyewa kamar hotel. Perilaku nelayan anak ini adalah perilaku konsumtif, sebagaimana yang di jelaskan oleh Wahyudi (2013: 30) "Perilaku konsumtif adalah perilaku seseorang yang tidak memikirkan hal yang lebih penting sebagai kebutuhannya tetapi lebih memikirkan hasrat atau keinginan untuk membeli benda benda yang tidak diperlukan demi kesenangan semata" kemudian tidak jauh berbeda dengan yang dijelaskan oleh (Lestari, 2006) perilaku Konsumtif adalah gaya hidup yang menganggap materi sebagai sesuatu yang dapat mendatangkan kepuasan tersendiri.

Nelayan anak merasa sudah puas dengan uang yang telah ia hasilkan sendiri. Ia bisa membeli apa saja yang ia mau dan yang ia inginkan. Gaya hidup yang terlihat berlebihan yang mengutamakan kesenangan duaniawi dan konsumtif. Peneliti menemukan fakta bahwa nelayan anak mengukur sesuatu dengan uang. Jika ia memiliki uang ia bisa melakukan segalanya.
Pada kenyataannya lebih banyak dampak negatif yang dilakukan dari pada dampak positifnya. Nelayan anak di Pasir Kandang pada umumnya tidak bersekolah lagi dan menjadi pengangguran. Banyak dari mereka yang membuat kekacauan di lingkungan Pasir Kandang, seperti berkelahi dengan anak Pasir Jambak, berjudi, minum-minuman keras, memakai pisau atau bendabenda tajam lainnya untuk berkelahi dan tindakan kriminalitas yang tidak wajar di lakukan seumurnya,

Hal ini disampaikan oleh Sugeng Arianto (2001) yang menyatakan dampak negatif dari anak putus sekolah, yaitu: kenakalan remaja, seperti pacaran, pencurian dan perkelahian, pesta miras, menonton ornografi dan mengganggu teman (Musfiqon, 2007:24).

Berdasarkan temuan peneliti di Kelurahan Pasie Nan Tigo, dari 30 orang yang di wawancarai, 10 orang dari nelayan anak tersebut telah melakukan hubungan di luar nikah dan bertanggung jawab untuk menikahi wanita yang di hamilinya dan bekerja sebagai nelayan. Nelayan anak memlih untuk putus sekolah, ia mengikuti pergaulan teman-temannya, terpengaruh atas teman, kurangnya perhatian orangtua, sudah bisa 
mencari uang sendiri, bisa membeli apa saja dengan uang sendiri dan tidak mau mendengar apa nasehat dari orangtua.

Banyak hal negatif yang dilakukan oleh nelayan anak sehingga kehidupan nelayan anak di Pasir Kandang ini tidak lah berubah menjadi lebih baik namun masa depan anak muda penerus bangsa di Pasir Kandang ini semakin memburuk. Seharusnya pada umur usia sekolah nelayan anak di Pasir Kandang dapat mengenyam pendidikan formal.

\section{KESIMPULAN}

Berdasarkan temuan penelitian yang penulis, maka dapat di simpulkan bahwa nelayan anak di Pasir Kandang Kelurahan Pasie Nan Tigo Kecamatan Koto Tangah Padang memilih bekerja sebagai nelayan dari pada bersekolah, karena ia sudah mampu menghasilkan uang sendiri dan sudah merasa puas dengan penghasilan yang ia dapatkan Hingga sekarang ini nelayan anak Pasir Kandang memilih untuk tidak melanjutkan pendidikannya, dan memiliki perilaku yang konsumtif.

\section{DAFTAR PUSTAKA}

Prayitno, Anshori Enjang. 2017. Fenomena Anak Putus Sekolah Di Kelurahan Pasie Nan Tigo Pasie Jambak.
Arifin, 2003. Undang-Undang Republik Indonesia Nomor 20 Tahun 2003 Tentang Sistem Pendidikan Nasional. Jakarta. Departemen Pendidikan Nasional Repubik Indonesia Tarman, Hengki. 2018. FaktorFaktor Penyebab Anak Putus Sekolah (Studi Kasus di Kelurahan Banuaran Kecamatan Lubuk Begalung Kota Padang). Universitas Negeri Padang

Lestari, A. 2006. Ada Perbedaan Perilaku Konsumtif Mahasiswa yang Berkepribadian Ekstrovet dengan Mahasiswa yang berkepribadian Introvet. Skripsi (Tidak Diterbitkan). Sumatera Utara Psikologi universitas Sumatera Utara

Musfiqon. (2007). Menangani yang putus sekolah. UMSIDA

Arianto, Sugeng. 2001. Dampak Negatif Anak Putus Sekolah

Wahyudi. 2013. Tinjauan tentang Perilaku Konsumtif remaja.Jurnal Sosiologi, Vol.1,No.4,2013:26-38.

Wahyudin, Agung. (2004). Pola Asuh orang tua nelayan dalam membimbing anak di desa Campurejo kecamatan panceng kabupaten gresik. Volume 02 Nomer 01. Skripsi. Fakultas Sosiologi Universitas Surabaya. 